\title{
Truthmaker Maximalism defended again ${ }^{1}$
}

\section{Eduardo Barrio and Gonzalo Rodriguez-Pereyra}

1. Truthmaker Maximalism is the thesis that every truth has a truthmaker. Milne (2005) attempts to refute it using the following self-referential sentence M:

M: This sentence has no truthmaker.

Milne's reasoning is as follows. Suppose that $\mathrm{M}$ has a truthmaker. Then it is true. So what it says is the case is the case. Hence $M$ has no truthmaker. On the supposition that $\mathrm{M}$ has a truthmaker, it has no truthmaker. By reductio ad absurdum, $\mathrm{M}$ has no truthmaker. But this is just what $\mathrm{M}$ says. Hence $\mathrm{M}$ is a truth without a truthmaker, and therefore Truthmaker Maximalism is false (Milne 2005: 222).

Rodriguez-Pereyra (2006) defended Truthmaker Maximalism by arguing that Milne's attempted refutation begs the question against Truthmaker Maximalism, since the latter implies that $\mathrm{M}$ is like the Liar, in which case one can say about $\mathrm{M}$ whatever one says about the Liar, for instance, that it does not express a proposition (RodriguezPereyra 2006: 263). ${ }^{2}$ Milne had argued against assimilating $M$ to the Liar because, unlike the Liar, $M$ itself gives rise to no outright inconsistency when treated as an ordinary sentence and subject to the usual rules of logic (Milne 2005: 223). But that $\mathrm{M}$ does not give rise to an outright inconsistency unless one assumes Truthmaker Maximalism does not mean that one is not then treating $M$ as an ordinary sentence or that one is not using the usual rules of logic; all it means is that one has added an extra assumption (Rodriguez-Pereyra 2006: 262).

Recently, Milne has tried to defend his refutation by arguing that the proof that $\mathrm{M}$ is a truth without truthmakers is essentially object level and not at all semantic, which, in

\footnotetext{
1 This paper was presented at the Work in Progress Seminar of the Buenos Aires Logic Group and at the Seminario de Metafísica, IIF, UNAM. We are very grateful to those audiences.

${ }^{2}$ Lopez de Sa and Zardini (2006) provided a different reply to Milne.
} 
his view, justifies the analogy between $M$ and the Gödel sentence rather than with the Liar (2013: 474, 475). Milne thinks that this leaves two options open to the defender of Truthmaker Maximalism. One is the 'deadly dull option' of claiming that $\mathrm{M}$ does not express a proposition; the other is to take exception with some aspects of the logic employed in Milne's reasoning.

In this note we shall argue that Milne's new effort does not refute Truthmaker Maximalism. In section 2 we shall argue that Milne is still begging the question against Truthmaker Maximalism. In section 3 we shall argue that, even assimilating M to the Liar does not force the truthmaker maximalist to maintain the 'dull option' that $\mathrm{M}$ does not express a proposition. There are other options open and they invalidate the logic that Mlne uses in his proof. In section 4 we shall argue that Milne's proof requires, contrarily to what he thinks, an implicit appeal to semantic principles and notions. In section 5 we shall point out that there are two important disimilarities between $M$ and the Gödel sentence. Section 6 is a brief summary and conclusion.

2. Let $\mathrm{T}$ be a theory of truthmakers that includes modal free-logic (with a free $\exists$ elimination rule and $\square$-elimination). Milne's proof in $\mathrm{T}$ is as follows:

$\begin{array}{llll}1 & (1) \quad \mathrm{M} \leftrightarrow \neg \exists \mathrm{x} \square(\exists \mathrm{y}(\mathrm{y}=\mathrm{x}) \rightarrow \mathrm{M}) & \text { Premiss } \\ 2 & (2) & \exists \mathrm{x} \square(\exists \mathrm{y}(\mathrm{y}=\mathrm{x}) \rightarrow \mathrm{M}) & \text { Assumption } \\ 3 & \text { (3) } \quad \square(\exists \mathrm{y}(\mathrm{y}=\mathrm{a}) \rightarrow \mathrm{M}) & \text { Assumption } \\ 4 & \text { (4) } \quad \exists \mathrm{y}(\mathrm{y}=\mathrm{a}) & \text { Explicit existence assumption } \\ 3 & \text { (5) } \quad \exists y(\mathrm{y}=\mathrm{a}) \rightarrow \mathrm{M} & 3 \text {-elimination } \\ 3,4 & \text { (6) } & \mathrm{M} & \\ 2 & \text { (7) } & \mathrm{M} & 4,5 \mathrm{MP}\end{array}$




$\begin{array}{llll}1,2 & \text { (8) } & \neg \exists \mathrm{x} \square(\exists \mathrm{y}(\mathrm{y}=\mathrm{x}) \rightarrow \mathrm{M}) & 1,7 \leftrightarrow \text {-elimination } \\ 1 & \text { (9) } & \neg \exists \mathrm{x} \square(\exists \mathrm{y}(\mathrm{y}=\mathrm{x}) \rightarrow \mathrm{M}) & 2,8 \text { weak reductio } \\ 1 & (10) \quad \mathrm{M} & 1,9 \leftrightarrow \text {-elimination } \\ 1 & \text { (11) } \quad \mathrm{M} \mathrm{\&} \neg \exists \mathrm{x} \square(\exists \mathrm{y}(\mathrm{y}=\mathrm{x}) \rightarrow \mathrm{M}) & 9,10 \text { \&-introduction }\end{array}$

The proof assumes only the material equivalence between $\mathrm{M}$ and the claim that $\mathrm{M}$ has no truthmaker, and some logical resources: free logic, MP, \&-introduction, $\square-$ elimination, weak reductio and the classical structural rules for the notion of consequence (Weakening, Contraction, and Cut).

Milne emphasises that there is no semantic term in this proof, and he thinks that this is of the utmost importance, since this shows, in his view, the aptness of the analogy of M with the Gödel sentence (Milne 2006: 475).

But the point that Truthmaker Maximalism makes $M$ as paradoxical as the Liar, since it makes the predicates 'is true' and 'has a truthmaker' equivalent, still remains. Even if Milne's proof is object level, it is still a fact that, if Truthmaker Maximalism is true, the sentence about which he is proving that it has no truthmaker, is a sentence that is as paradoxical as the Liar, and for the same reasons as the Liar is paradoxical. For if $\mathrm{M}$ has a truthmaker, given Truthmaker Maximalism, $\mathrm{M}$ is true, in which case what it says is the case and so it has no truthmaker. But if it has no truthmaker, given Truthmaker Maximalism, $\mathrm{M}$ is not true, in which case what it says is not the case and so it has a truthmaker. Thus $\mathrm{M}$ has a truthmaker if and only if it has no truthmaker. This is a semantic argument, not an object level one. But the fact that Milne's is object level does not invalidate this semantic argument. Nor does it show that $\mathrm{M}$ is like the Gödel sentence rather than the Liar. To show this, Milne needs an independent refutation of Truthmaker Maximalism, something he has not provided. Without such an independent proof, the claim that the proof above shows that $\mathrm{M}$ is like the Gödel sentence rather than the Liar begs the question against Truthmaker Maximalism. 
3. Given that Truthmaker Maximalism assimilates $M$ to the Liar, the truthmaker maximalist can say about $\mathrm{M}$ whatever he says about the Liar. And one thing some people say about the Liar is that it fails to express a proposition. So one thing the truthmaker maximalist can say about $\mathrm{M}$ is that it does not express a proposition. This Milne considers to be a dull option (2006: 475). But this is not the only thing the truthmaker maximalist can say about M. Another thing the truthmaker maximalist can say is that $\mathrm{M}$ expresses a proposition that is neither true nor false. Recently some authors have developed paracomplete theories that can be used to assign a neithertrue-nor-false value to M (Kripke 1975, Field 2008).

Indeed paracomplete approaches seem to validate the intuition that a sentence like $\mathrm{M}$ is neither true nor false. In general, a three-valued model for a first-order language L is just like a classical model, except that the function $I$ assigns, to each $n$-place relation symbol, a function from $D^{n}$ to $\{\mathbf{t}, \mathbf{f}, \mathbf{n}\}$. Officially $\mathbf{t}($ rue $), \mathbf{f}($ alse $)$ and $\mathbf{n}$ (either) are three truth values, but $\mathbf{n}$ can be thought of as the absence of a truth value. In both the weak and strong Kleene schemes negation is treated identically: $\neg \mathbf{t}=\mathbf{f}, \neg \mathbf{f}=\mathbf{t}$, and $\neg \mathbf{n}=\mathbf{n}$. Using this framework, Kripke explains his view of groundedness thus:

In general, if a sentence... asserts that (all, some, most. etc.) of the sentences of a certain class $\mathrm{C}$ are true, its truth value can be ascertained if the truth values of the sentences in the class $\mathrm{C}$ are ascertained. If some of these sentences involve the notion of truth, their truth value must in turn be ascertained by looking at other sentences, and so on. If ultimately this process terminates in sentences not mentioning the concept of truth, so that the truth value of the original statement can be ascertained, we call the original sentence grounded; otherwise ungrounded (Kripke 1975: 693-94).

Thus, according to Kripke, a sentence whose truth-value is not determined on the basis of facts not involving the concept of truth is an ungrounded sentence. It is clear that $\mathrm{M}$ is ungrounded in Kripke's sense: its truth-value depends on a semantic fact since it depends on whether it has a truthmaker. So $\mathbf{M}$ receives $\mathbf{n}$ as its truth-value in 
what Kripke calls the minimal fixed-point. But if $\mathrm{M}$ is neither true nor false, then Milne's proof uses a rule he is not entitled to, namely weak reductio, since weak reductio is not valid for sentences that are neither true nor false. Thus the logic Milne uses might have to be revised, depending on what the truthmaker maximalist decides to say about M. ${ }^{3}$

4. One way in which Milne supports his assimilation of $M$ to the Gödel sentence is that his proof is essentially object level and not semantic (2013: 474, 475). But although the proof itself does not explicitly use semantic principles, it cannot be understood unless one appeals to semantic notions and principles. That is, his proof presupposes semantic notions and principles, and this is so for several reasons.

Firstly, the initial premise in the proof is a material equivalence. But why should we accept it? The only reason is that ' $\mathrm{M}$ ' is supposed to denote the sentence $\neg \exists \mathrm{x} \square(\exists \mathrm{y}(\mathrm{y}$ $=\mathrm{x}) \rightarrow \mathrm{M}$ ) or, in other words, that ' $\mathrm{M}$ ' is supposed to mean that it has no truthmaker. Without implicit grasp of this idea, which is explicit in Milne's informal reasoning that $\mathrm{M}$ is a truth without truthmaker, there is no reason to accept the first premise and no reason to accept that the conclusion of the proof is a counterexample to Truthmaker Maximalism. Indeed premise (1) is a potential counterexample to Truthmaker Maximalism only in virtue of what it means.

Secondly, the natural formulation of premise (1) features a truth-predicate in the consequent of the right-hand side of the biconditional, thus: $\mathrm{M} \leftrightarrow \neg \exists \mathrm{x} \square(\exists \mathrm{y}(\mathrm{y}=\mathrm{x}) \rightarrow$ $\left.\operatorname{Tr}\left({ }^{\prime} \mathrm{M}^{\prime}\right)\right)$. This is because M says that it has no truthmaker. And the truthmaking idea is an idea about the dependence of truth upon being. Thus a reference to truth seems ineliminable from any sentence that speaks about truthmakers.

\footnotetext{
${ }^{3}$ It should be noted that Milne explores abandoning the rule of Contraction. But this is odd because abandoning the rule of Contraction is normally associated to the pathological character of sentences. It is strange to object to Contraction, unless one has already assumed that M is analogous to the Liar. It is strange then that at the end of his article Milne says that there are two options: either to abandon Contraction or to assume that $\mathrm{M}$ is genuinely paradoxical; for the motivation to abandon Contraction lies in taking M to be genuinely paradoxical (Zardini 2011, Beall and Murzi 2013, Murzi and Shapiro forthcoming, Shapiro forthcoming).
} 
Thirdly, even if it were thought that premise (1) can be obtained via diagonalization on some open sentence, this would require either having a truth-predicate in the open sentence - thus diagonalizing on $\exists \mathrm{x} \square\left(\exists \mathrm{y}(\mathrm{y}=\mathrm{x}) \rightarrow \operatorname{Tr}\left({ }^{\circ} \ldots{ }^{\prime}\right)\right)$ - or having a modal predicate $N E C$ instead of a modal operator - thus diagonalizing on $\exists \mathrm{xNEC}\left({ }^{\circ} \exists \mathrm{y}(\mathrm{y}=\mathrm{x})\right.$ $\left.\rightarrow(\ldots)^{\prime}\right) .{ }^{4}$ The first strategy would produce, via diagonalization, $\left(1^{*}\right)$ :

$$
\mathrm{M} \leftrightarrow \neg \exists \mathrm{x} \square\left(\exists \mathrm{y}(\mathrm{y}=\mathrm{x}) \rightarrow \operatorname{Tr}\left({ }^{\circ} \mathrm{M}^{\prime}\right)\right) .^{5}
$$

The second strategy would produce, via diagonalization, $\left(1^{* *}\right)$ :

$\left(1^{* *}\right) \quad \mathrm{M} \leftrightarrow \neg \exists \mathrm{xNEC}\left({ }^{\prime} \exists \mathrm{y}(\mathrm{y}=\mathrm{x}) \rightarrow(\mathrm{M})^{\prime}\right)$

The problem is that, using $\left(1^{*}\right)$ or $\left(1^{* *}\right)$ to prove the conclusion $(11)$ would require a semantic principle to eliminate the new predicate. Thus, using $\left(1^{*}\right)$ one would get $\operatorname{Tr}\left({ }^{\prime} \mathrm{M}\right.$ ') in a corresponding step $\left(6^{*}\right)$ and one would need to eliminate the predicate $\operatorname{Tr}\left({ }^{\prime} .\right.$. '), presumably using a principle of semantic descent. Something similar would occur if we started the proof with $\left(1^{* *}\right){ }^{6}$ This case is aggravated by the risk of falling into the well-known Montague paradox. ${ }^{7}$ And what complicates matters further is that this would require showing that modal predicates are capturable in PA. But it is usually agreed that modal predicates are not capturable in PA and that only as a license is diagonalization applied to predicates expressing modal notions.

Fourthly, there is an implicit appeal in Milne's proof to the principle of semantic ascent, one of the semantic principles used in the derivation of a contradiction from

\footnotetext{
${ }^{4}$ We prefer not to introduce too many technicalities at this point but we should like to note that, to be strict, one ought to use Feferman's dot notation to allow quantification into formulae containing quotation terms (Feferman 1991: 13).

${ }^{5}$ We write 'M' to denote the numeral of the Gödel number of M provided some fixed coding.

${ }^{6}$ Note that in step (5) of his proof Milne needs the rule of necessity-elimination. This is a rule that governs the use of the necessity operator. If he were using a predicate of necessity he would need a corresponding rule of modal descent to eliminate the predicate.

7 Montague (1963) showed that any theory that is closed under the necessitation rule and accepts $\mathrm{NEC}\left({ }^{\prime} \mathrm{A}\right.$ ') $\rightarrow \mathrm{A}$ is inconsistent.
} 
the Liar. For M \& $\neg \exists \mathrm{x} \square(\exists \mathrm{y}(\mathrm{y}=\mathrm{x}) \rightarrow \mathrm{M})$ is no counterexample to Truthmaker Maximalism unless $M$ is true. Thus one needs to implicitly assume that if $M$ then $M$ is true, and this is the principle of semantic ascent. The point can be seen in a different way: Milne's proof shows that given a theory of truth-makers T, there is a proof of M in $\mathrm{T}$, i.e. $\mathrm{T} \vdash \mathrm{M}$. But unless the soundness of $\mathrm{T}$ is assumed, there is no guarantee that the 'theorems' of $\mathrm{T}$ are true. Without the assumption that $\mathrm{T}$ is sound, only an implicit assumption of the principle of semantic ascent (if $T \vdash M$ then $T \vdash \operatorname{Tr}(M)$ ) ensures that $\mathrm{M}$ is a truth without a truthmaker.

Since Milne thinks that the fact that his proof is essentially object-level and not at all semantic justifies the assimilation of $M$ to the Gödel sentence, we have here shown that this assimilation lacks its intended support. Perhaps there is another sense in which Milne's proof is object-level and not semantic, but if so Milne needs to say what sense this is and why this supports assimilating $M$ to the Gödel sentence rather than the Liar.

5. But not only does Milne not properly support the analogy between $M$ and the Gödel sentence, these two sentences are clearly disanalogous in at least two important senses. Firstly, the Gödel sentence is shown to be undecidable through certain principles (the axioms of Peano Arithmetic) that are taken to be constitutive of the theory to which the Gödel sentence belongs. But although we know those principles, we do not know what the constituve principles of the theory to which $\mathrm{M}$ belongs are.

Secondly, the Gödel sentence is undecidable in Peano Arithmetic. Since the Gödel sentence is undecidable in Peano Arithmetic, the Gödel sentence cannot be proved in Peano Arithmetic. But for $M$ to be analogous to the Gödel sentence, it should not be provable in the truthmaker theory $\mathrm{T}$, but if Milne is right, $\mathrm{M}$ is provable in $\mathrm{T}$.

6. Milne takes himself to have refuted Truthmaker Maximalism. Essential to his refutation is that $M$ is like the Gödel sentence and unlike the Liar, and one way in which Milne supports this assimilation is through the claim that his proof is essentially object-level and not semantic. But we have argued (a) that Milne is still 
begging the question against Truthmaker Maximalism, (b) that even assimilating $M$ to the Liar does not force the truthmaker maximalist to maintain the 'dull option' that $\mathrm{M}$ does not express a proposition, (c) that Milne's proof requires an implicit appeal to semantic principles and notions, which means Milne lacks support for his assimilation of $\mathrm{M}$ to the Gödel sentence, and (d) that $\mathrm{M}$ is dissimilar, in at least two important respects, from the Gödel sentence. Thus Truthmaker Maximalism has not been refuted.

University of Buenos Aires/CONICET

eabarrio@gmail.com

Oriel College, Oxford

gonzalo.rp21@gmail.com

References:

Beall, J. and Murzi, J. 2013. 'Two Flavors of Curry's Paradox', The Journal of Philosophy CX: 143-65.

Feferman, S. 1991. 'Reflecting on Incompleteness', Journal of Symbolic Logic, 56: 149.

Field, H. 2008. Saving Truth from Paradox. Oxford University Press: Oxford.

Kripke, S. 1975. 'Outline of a Theory of Truth', Journal of Philosophy 72: 690-716.

Lopez de Sa, D. And Zardini, E. 2006. 'Does this sentence have no truthmaker?', Analysis 66: 154-57.

Milne, P. 2005. 'Not Every Truth has a Truthmaker', Analysis 65: 221-24.

Milne, P. 2013. 'Not Every Truth has a Truthmaker II', Analysis 73: 473-81. 
Montague, R. 1963. 'Syntactical treatments of modality, with corollaries on reflexion principles and finite axiomatizability', Acta Philosophica Fennica 16: 153-67.

Murzi, J. and Shapiro, L. Forthcoming, 'Validity and Truth-preservation', in H. G. T. Achourioti F. Fujimoto and J. Martinez-Fernandez (eds), Unifying the Philosophy of Truth, Springer.

Rodriguez-Pereyra, G. 2006. 'Truthmaker Maximalism Defended', Analysis 66: 26064.

Shapiro, L. 2011. 'Deflating Logical Consequence', Philosophical Quarterly 61: 32042.

Shapiro, L. Forthcoming. 'Naive Structure, Contraction and Paradox', Topoi.

Zardini, E. 2011. 'Truth without Contra(di)ction', Review of Symbolic Logic 4: 498535. 